\title{
Effect of Nitrogen on Solidification Cracking Resistance in ERNiCr-3 Weld Metal
}

\author{
This study investigated the solidification cracking \\ susceptibility of Filler Metal 82 in one heat
}

BY M. R. ORR, C. FINK, .J. C. LIPPOLD, AND F. ARGENTINE

\begin{abstract}
Additions of nitrogen were made to ERNiCr-3 (FM 82) weld metal to investigate the effect on weld metal microstructure and solidification cracking susceptibility. Weld samples were prepared with different argon-nitrogen shielding gas mixtures to produce nitrogen variations in the weld metal. The cast pin tear test (CPTT) was then used to evaluate solidification cracking susceptibility as a function of weld metal nitrogen content. Phase fraction and composition of constituents in the final solidification microstructure were characterized via optical and electron microscopy. Thermodynamic (Scheil) calculations were performed to determine the phase formation during solidification, associated solidification path, and solidification temperature range. Solidification cracking susceptibility was found to increase significantly with increasing nitrogen content. The overall amount of second phase in the solidified microstructure increased when nitrogen was added to the weld metal. Small skeletal constituents in the interdendritic regions, primarily $\mathrm{Nb}$-rich carbides ( $\mathrm{NbC}$ ), were more frequently observed with increasing weld metal nitrogen content. Larger cuboidal Ti-rich nitrides (TiN) and carbonitrides (Ti, Nb)(N, C) were found only when nitrogen was added to the weld metal. Their location in dendrite core regions indicates formation during an earlier stage of the solidification process. Scheil calculations confirmed the strong effect of nitrogen additions on the amount and sequence of phase formation during solidification of ERNi$\mathrm{Cr}-3$ weld metal. High nitrogen levels ( $>100 \mathrm{ppm}$ ) facilitate primary nitride formation prior to the solidification of the gamma $(\gamma)$ dendrites, and increase the amount of phase constituents in the solidification microstructure. The presence of nitrogen also shifts the start of the eutectic $\gamma / \mathrm{NbC}$ formation at the end of solidification to lower temperatures, which results in an increase in the solidification temperature range. This occurs at much lower nitrogen levels (>25 ppm) and correlates with the observed increase in solidification cracking susceptibility.
\end{abstract}

\section{KEYWORDS}

- Solidification Cracking • ERNiCr-3 • Cast Pin Tear Test - Nitrogen

\section{Introduction}

Filler Metal 82 (ERNiCr-3) is used for the joining of nickel-based alloys and dissimilar metal welds between stainless steel and low-alloy steel or carbon steel components (Ref. 1). High-temperature and creep-rupture strengths at elevated temperatures, good corrosion resistance, and the ability to bridge differing coefficients of thermal expansion (CTE) in dissimilar metal welds contribute to its use in a wide variety of applications. Filler Metal 82 is also often selected because it is generally considered resistant to solidification cracking under low and moderate restraint conditions (Refs. 2-4).

Industrial experience with thick-section, high-restraint weld overlays has shown variability in solidification cracking resistance among different heats of Filler Metal 82. Recent work indicated an effect of interstitial element content on solidification cracking resistance (Ref. 5). In particular, heats with low nitrogen content showed superior resistance to solidification cracking. Resistant heats were found to experience a higher degree of crack backfilling (Ref. 5). Backfilling is observed in weld metals to promote partial or entire crack healing due to sufficient fraction of liquid at the end of solidification that flows into newly formed cracks or voids (Refs. 6-9). Differences among heats were also found in the nature of constituents in the solidification microstructure that correlated with differences in nitrogen and possibly carbon content (Ref. 5). Carbon is an intentional addition in nickel base filler metals, typically at levels below $0.06 \mathrm{wt}-\%$. Nitrogen is specified in some filler metal compositions at levels below $0.04 \mathrm{wt}-\%$, but it can vary widely depending on alloy type and melting practice.

This study investigated the solidification cracking susceptibility, and the amount and composition of phase constituents upon solidification in one heat (constant carbon content) of Filler Metal 82 as a function of nitrogen additions. The objectives of this study were to 1 ) evaluate the effect of nitrogen content on solidification cracking resistance, and 2) determine differences in phase formation during solidification at different weld metal nitrogen levels. A better understanding of the effect of interstitial elements (nitrogen and carbon) may further explain heat-to-heat weldability variations experienced in industry. This will also 


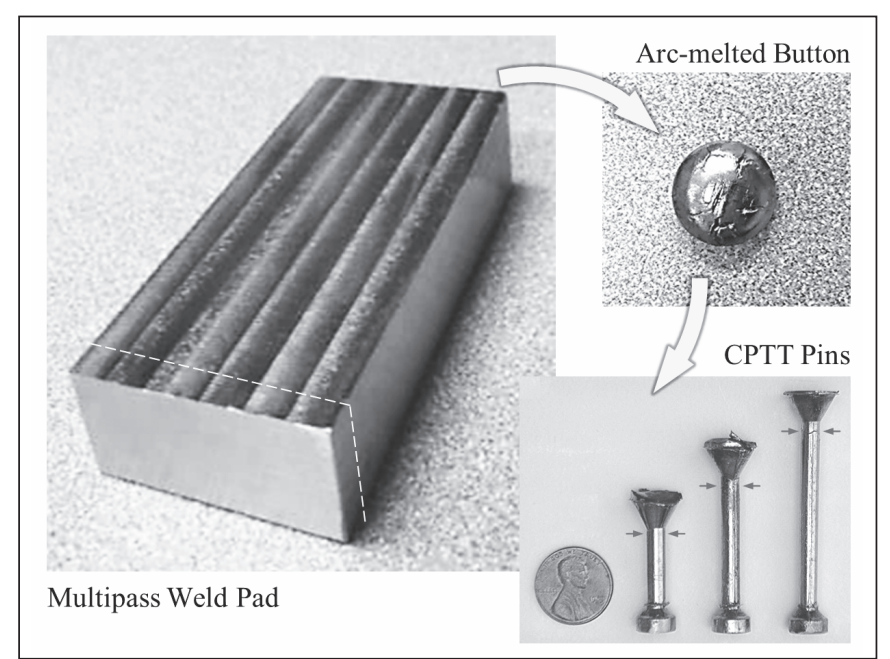

Fig. 1-Multipass weld pads were sectioned and remelted into buttons, which were then cast into pins of different lengths using the cast pin tear test (CPTT).

potentially allow filler metals to be compositionally modified (interstitial content) to prevent solidification cracking under high-restraint conditions.

\section{Experimental Procedures}

\section{Materials and Weld Metal Preparation}

The effect of nitrogen on solidification cracking resistance was studied on ERNiCr-3 (FM 82) heat number YT0159. The nominal composition is provided in Table 1 . Note the low nitrogen content of $16 \mathrm{ppm}$.

Five multipass weld pads were prepared using automated hot wire gas tungsten arc welding (AGTAW-HT). Welds were made with a welding current of $295 \mathrm{~A}$, voltage of $12 \mathrm{~V}$, and travel speed of $3.4 \mathrm{~mm} / \mathrm{s}$. Different $\mathrm{Ar} / \mathrm{N}_{2}$ shielding gas mixtures were used to produce variations in nitrogen content in the weld metal. Nitrogen gas was added to the argon shielding gas at levels of $0,0.2,0.4,1$, and 5 vol- $\% \mathrm{~N}_{2}$, respectively. LECO combustion analysis was used to measure the resulting nitrogen content in the as-deposited weld metals.

\section{Cast Pin Tear Test}

The cast pin tear test (CPTT) was used to evaluate the solidification cracking resistance as a function of nitrogen content. The CPTT is a self-restrained solidification cracking test that utilizes an induction levitation coil to melt and feed the material of interest into pin-shaped copper molds of varying lengths. Details on the test procedure can be

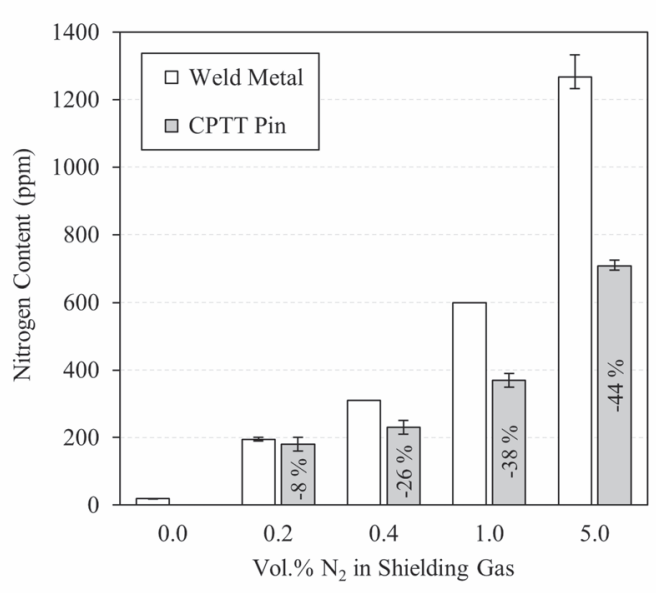

Fig. 2 - Measured nitrogen content in as-deposited weld metals as a function of vol-\% $\mathrm{N}_{2}$ in the shielding gas mixture, and measured nitrogen in cast pins showing relative nitrogen loss (in \%) due to remelting.

found elsewhere (Refs. 3, 5, 10). Cracking in the solidifying pin is induced by strain buildup during solidification as a function of the copper mold length. The lower cracking threshold (LCT), i.e., the longest pin length where no cracking is observed, is utilized as the quantitative measure of solidification cracking resistance.

In preparation for the CPTT, the multipass welds were sectioned and remelted into buttons of 10-15 g using a gas tungsten arc melting process under argon atmosphere. These buttons were used as input material for the CPTT, melted in the levitation coil, and cast into pin-shaped copper molds - Fig. 1. Up to five pins were cast for each weld metal at a single mold length to acquire adequate statistics. Pin lengths in the range of 0.5 to $1.5 \mathrm{in}$. were used. The pins were inspected for cracking under a stereomicroscope. LECO combustion analysis was used to measure the nitrogen content in selected cast pins.

\section{Microstructural Characterization}

Sectioned cast pins were mechanically polished and electrolytically etched with $10 \%$ chromic acid at $3 \mathrm{~V}$ for 2 to $5 \mathrm{~s}$ for optical and electron microscopy. Secondary electron imaging and compositional analysis were performed in a FEI/Philips XL-30 field emission scanning electron microscope (SEM) equipped with $\mathrm{x}$-ray energy-dispersive spectroscopy (XEDS). Volume (area) fraction of second phases in the solidification microstructure was determined via image processing and analysis (ASTM E1245-03) using ImageJ software. A minimum of 15 scanning electron micrographs (2000x) from cross-sectioned cast pins (1.125-in. pin length) was used for image analysis.

Table 1 - Nominal Composition of ERNiCr-3 (FM 82) Heat YT0159. (All Values in wt-\%.)

\begin{tabular}{|c|c|c|c|c|c|c|c|}
\hline $\begin{array}{c}\text { Al } \\
0.055\end{array}$ & $\begin{array}{c}C \\
0.055\end{array}$ & $\begin{array}{c}\text { Co } \\
0.004\end{array}$ & $\begin{array}{c}\mathrm{Cr} \\
20.39\end{array}$ & $\begin{array}{c}\mathrm{Cu} \\
0.004\end{array}$ & $\begin{array}{l}\mathrm{Fe} \\
1.14\end{array}$ & $\begin{array}{l}\text { Mn } \\
3.25\end{array}$ & $\begin{array}{c}\text { Mo } \\
0.003\end{array}$ \\
\hline $\mathrm{N}$ & $\mathrm{Nb}$ & $\mathrm{Ni}$ & $\mathrm{P}$ & S & $\mathrm{Si}$ & $\mathrm{Ti}$ & V \\
\hline 0.0016 & 2.29 & 72.3 & $<0.005$ & $<0.001$ & 0.11 & 0.42 & 0.007 \\
\hline
\end{tabular}




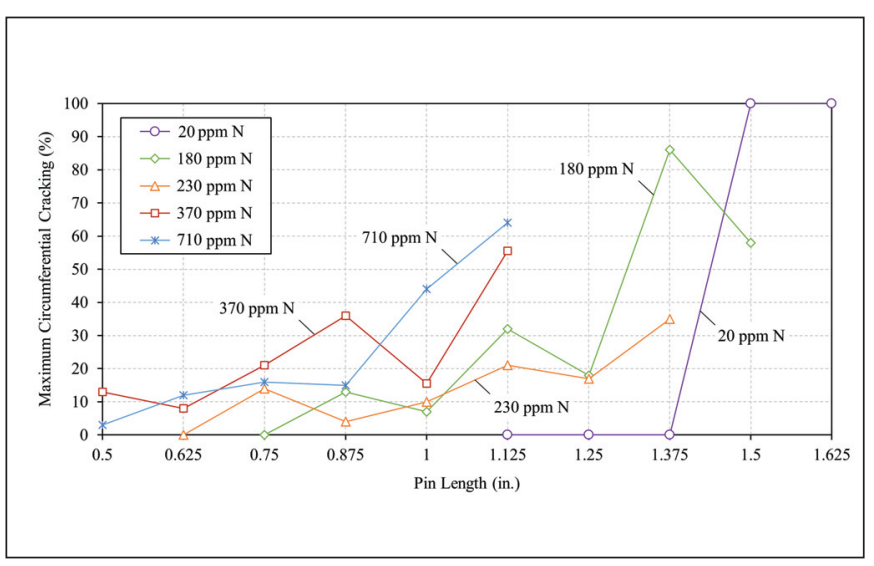

Fig. 3-Percent cracking in the CPTT pins with different nitrogen levels as a function of the cast pin length. The lines represent the maximum circumferential cracking observed over all tested pins at an individual pin length.

\section{Computational Modeling}

Nonequilibrium Scheil solidification modeling was performed in Thermo-Calc version 2017a and TCNi8 thermodynamic database to calculate solute redistribution, phase formation during solidification, associated solidification path, terminal second-phase content, and solidification temperature range. Scheil-Gulliver solidification assumes local equilibrium at the planar solid/liquid interface, no diffusion of substitutional alloying elements in the solid phase $\left(D_{S}=\right.$ 0 ), and complete mixing in the liquid $\left(D_{L}=\infty\right)$. Scheil calculations, therefore, represent the worst case in terms of microsegregation of elements to the solidification grain and subgrain boundaries, but have been shown to be reasonably accurate for most cooling rate conditions associated with fusion welding of nickel-based alloys (Ref. 11). Calculations were performed for the nominal composition of ERNiCr-3 (FM 82) heat YT0159 (see Table 1) with variations in nitrogen content between 0 and $800 \mathrm{ppm}$. Only elements $\mathrm{Ni}, \mathrm{C}$, $\mathrm{Cr}, \mathrm{Fe}, \mathrm{Mn}, \mathrm{N}, \mathrm{Nb}, \mathrm{Si}$, and Ti were included in the modeling to speed simulation time. Carbon and nitrogen were entered as fast-diffusing elements, i.e., backdiffusion of these elements into the solid phase was considered. Calculations were performed by decreasing the temperature from $2000^{\circ} \mathrm{C}$ stepwise in $1^{\circ} \mathrm{C}$ intervals until the fraction of solid phase $\left(f_{s}\right)$ in the system reached 0.99. All available phases were allowed to form during solidification, with the exception of the GAS and HCP_A3 phases. Including these phases resulted in inconsistent results due to evaporation of nitrogen from the liquid, and the formation of $\mathrm{Nb}$ - and $\mathrm{Cr}$-rich carbides (HCP) that were not observed experimentally.

\section{Results}

\section{Nitrogen Content in As-Deposited Weld Metal and CPTT Pins}

Figure 2 shows the measured nitrogen content in the asdeposited weld metals as a function of volume percent of nitrogen gas in the shielding gas mixture. Welding with pure argon shielding gas resulted in a nitrogen content of $20 \mathrm{ppm}$

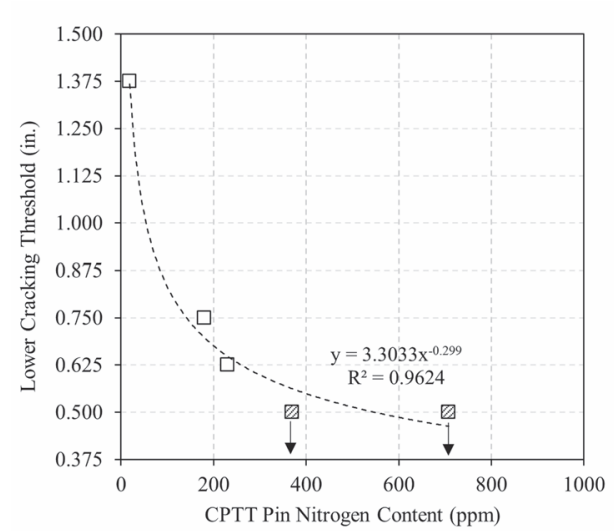

Fig. 4 - CPTT cracking threshold (LCT) as a function of the nitrogen content in the cast pins. Note the severe drop in cracking threshold with increasing nitrogen. As LCT decreases, cracking susceptibility increases.

in the as-deposited weld metal. The nitrogen content rapidly increases when nitrogen gas is added to the shielding gas. A maximum weld metal nitrogen content of $1300 \mathrm{ppm}$ was measured at 5 vol- $\% \mathrm{~N}_{2}$ in the shielding gas mixture. As shown, the amount of nitrogen measured in cast pins after the CPTT was considerably lower than in the as-deposited weld metal. Nitrogen was lost during both the button-melting process and the melting in the CPTT levitation coil. The percentage loss increased with increasing nitrogen content in the as-deposited weld metal. All subsequent results presented in this study consider the nitrogen content measured in the cast pins.

\section{Solidification Cracking Resistance}

Results of the CPTT are presented in Fig. 3. Cracking in the cast pins is shown as the maximum circumferential cracking observed over all tested pins as a function of the pin length. The nitrogen content in the legend box corresponds to measurements in the cast pins. At a low nitrogen content of $20 \mathrm{ppm}$, the LCT of 1.375-in. pin length indicates a high resistance to solidification cracking. This correlates well with industry experience. Low-nitrogen heat YT0159 has been shown to be resistant to solidification cracking in actual fabrication welding under high restraint conditions. It is apparent that there is a significant reduction in LCT with increasing nitrogen content - Fig. 4. A nine-fold increase in nitrogen content from 20 to $180 \mathrm{ppm}$ yielded a severe decrease in LCT to $0.75 \mathrm{in}$. Further increase in nitrogen content reduced the LCT to below 0.5 in., which is the smallest mold length currently available for the CPTT system. Thus, the actual threshold could not be determined for nitrogen contents more than $300 \mathrm{ppm}$. Weld metals with LCT values less than $1.0 \mathrm{in}$. are considered susceptible to solidification cracking.

\section{Distribution and Composition of Phase Constituents}

Optical and electron microscopy revealed differences in the microstructure of YT0159 weld metal as a function of 

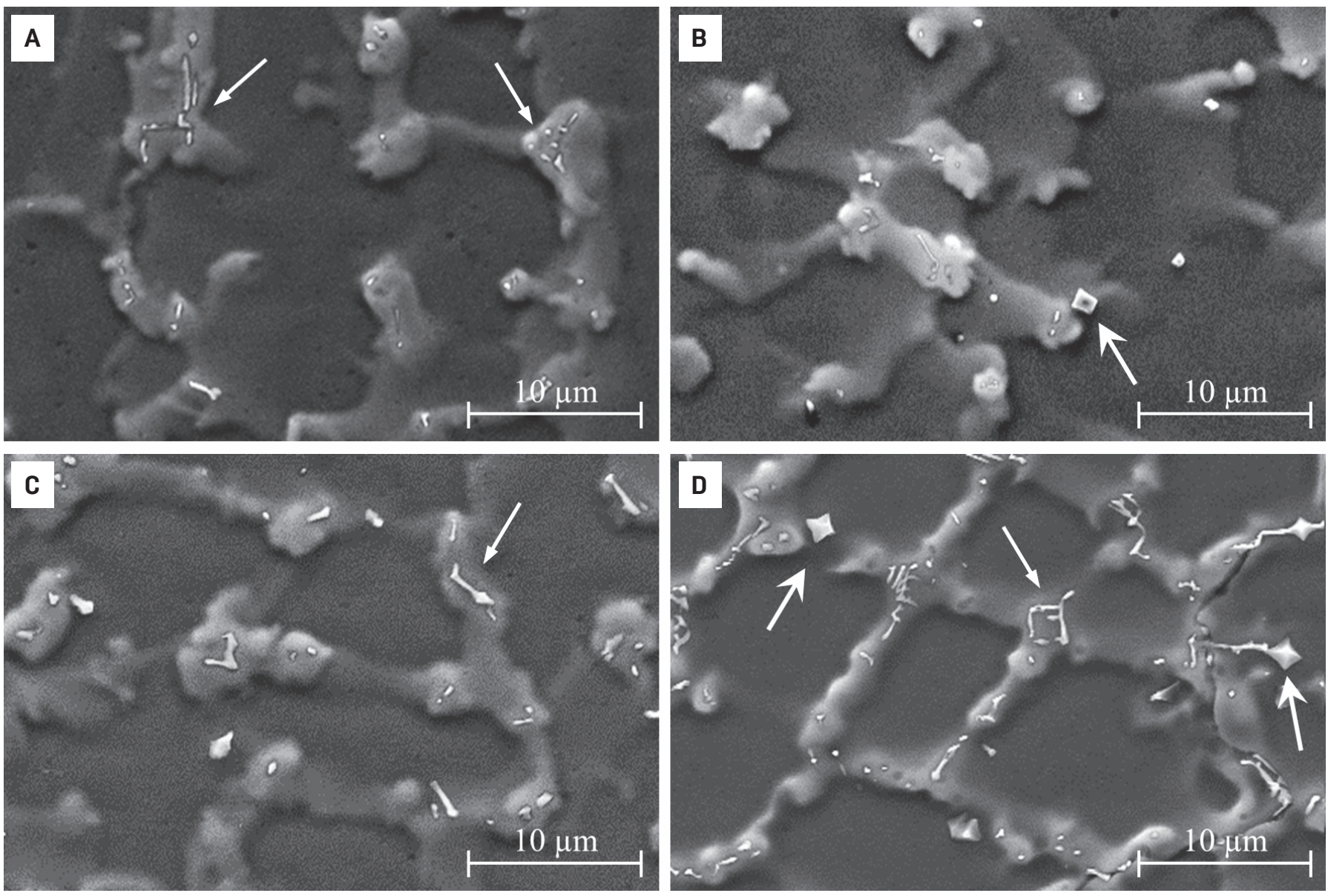

Fig. 5 - Scanning electron micrographs of phase constituents in cast pins as a function of nitrogen content: A - 20 ppm; B - 180 ppm; C -370 ppm; $D-710$ ppm. Skeletal, interdendritic phase (small arrows), and cuboidal, primary constituents (larger arrows). All images acquired from pins of 1.125-in. pin length.

nitrogen content. Figure 5A-D shows the morphology of phase constituents in the fully austenitic (gamma $(\gamma)-\mathrm{Ni}$ ) matrix with increasing nitrogen. Scanning electron micrographs were taken from midcross sections of cast pins of 1.125-in. pin length, and are representative of the microstructure in the solidified pins. It is apparent from the micrographs that the overall level of phase constituents increases with increasing nitrogen content. Small skeletal or elongated constituents (small arrows) were observed along grain boundaries or aligned in the interdendritic regions. The fraction of interdendritic phase increases with increasing nitrogen. Larger particles with square to cuboidal shapes (larger arrows) were found at a nitrogen content of $180 \mathrm{ppm}$ and were more frequently observed at higher nitrogen content. Most of these are located in dendrite core regions.

Compositional mapping (XEDS) was performed on numerous constituents in interdendritic and dendrite core regions in pin microstructures of all nitrogen levels. It should be noted that these measurements are only approximate because the size of the constituents was often smaller than the interaction volume of the electron beam in the SEM, and the low atomic weight of nitrogen and carbon makes its detection and quantification by XEDS difficult. With these limitations in mind, the skeletal phase aligned interdendritic or along solidification grain boundaries appears to be primarily the Nb-rich carbide $(\mathrm{NbC})$ type - Fig. 6A. In some cases, slight enrichment in titanium indicates mixed composition $(\mathrm{Nb}, \mathrm{Ti})(\mathrm{C}, \mathrm{N})$ carbonitrides. The larger, square- or rectangular-shaped particles appear to be Ti-rich nitrides (TiN) or complex $(\mathrm{Ti}, \mathrm{Nb})(\mathrm{C}, \mathrm{N})$ carbonitrides. These carbonitrides have a higher content of titanium and a lower content of niobium than the skeletal interdendritic phase - Fig. 6B. The nucleation of $\mathrm{NbC}$ carbide arms on cuboidal nitrides (carbonitrides) was frequently observed close to interdendritic regions and grain boundaries - Fig. 6C.

\section{Fraction of Phase Constituents}

Results from the image analysis in Fig. 7 confirm the visual evidence obtained from Fig. 5 showing the overall amount of constituents increases with increasing nitrogen content. An effort was made to differentiate between the skeletal interdendritic and the larger, primary dendritic phase. However, it should be noted that these phase fraction measurements are only approximate, due to the inherent difficulties of acquiring accurate measurements at such low quantities. It is apparent that the amount of skeletal interdendritic phase increased significantly at a nitrogen content of $370 \mathrm{ppm}$ and above. Note that the initial increase in phase fraction up to about $230 \mathrm{ppm}$ of nitrogen is rather 

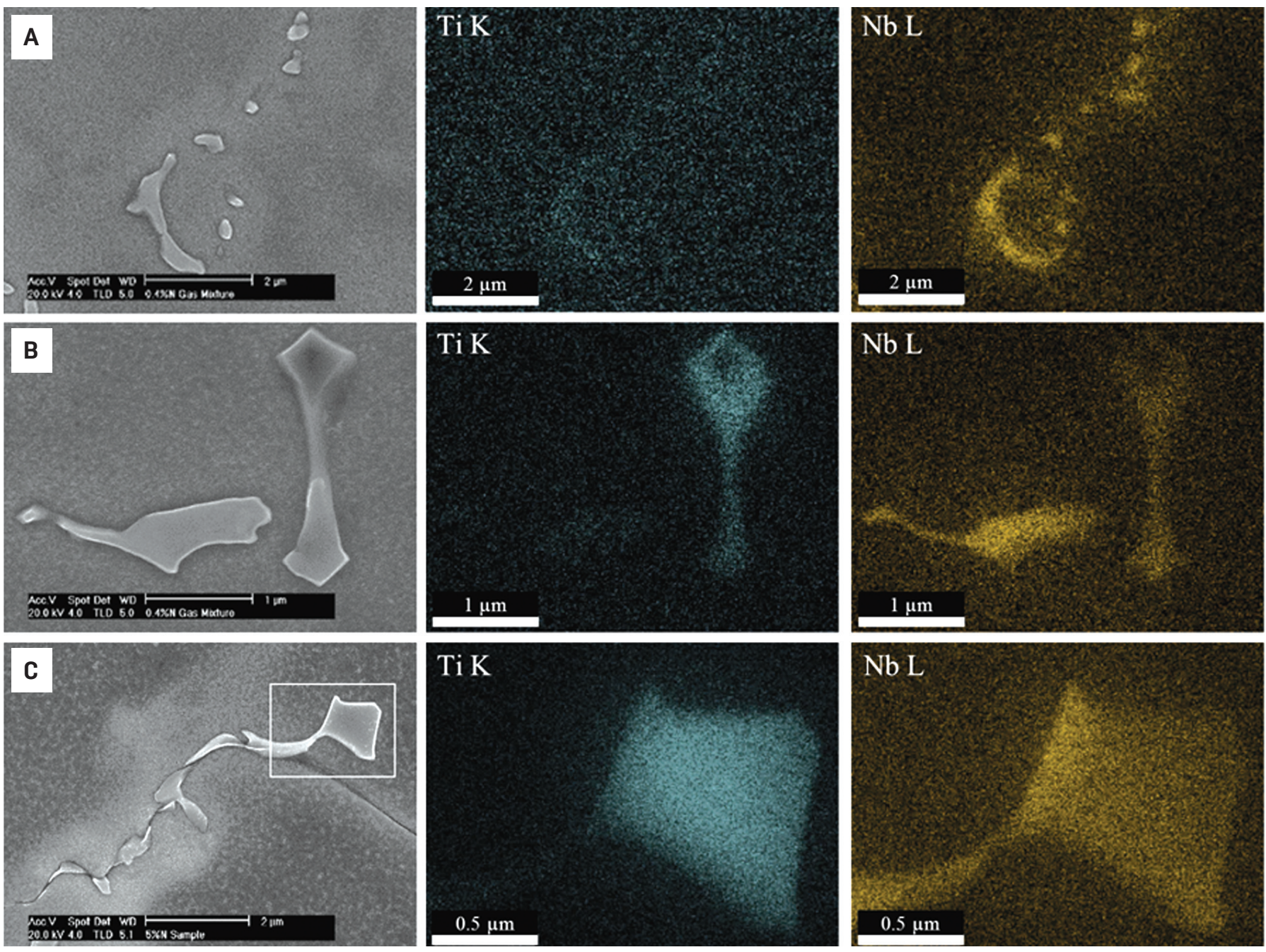

Fig. 6 - Scanning electron micrographs and elemental chemical mapping obtained by XEDS of skeletal and cuboidal phase constituents near interdendritic regions and grain boundaries in cast pins of different nitrogen content: $A$ and B - 230 ppm; C - 370 ppm.

small. The amount of larger, primary dendritic particles also increased with increasing nitrogen content. Their phase fraction remains small as compared to the amount of interdendritic phase present. Table 2 provides information on the statistical significance of the measured values. The $95 \%$ confidence interval predicts intersections between the data at low nitrogen content. The relative accuracy is less than $30 \%$ for all nitrogen levels, which indicates a low field-tofield variability and an overall representative data set.

\section{Backfilling of Solidification Cracks}

Evidence of backfilling was scarce in cross-sectioned cast pins at all nitrogen levels. No significant difference in the degree of backfilling was found based on differences in nitrogen. Figure 8 shows some of the few backfilled cracks observed in pins of different nitrogen content. All micrographs are from pin lengths at the LCT, where no surface cracking was observed. Based on previous research, backfilling has been shown to influence cracking susceptibility in pins at the LCT (Ref. 9). In all cases where crack healing was observed, backfilled regions were found along solidification grain boundaries facilitating partial or full healing of preexisting cracks close to the surface.

\section{Scheil Solidification Modeling}

Results from Scheil solidification simulations for compositions with different nitrogen content are shown in Table 3. Nitrogen additions are not predicted to affect the gamma $(\gamma)$ start temperature, but have a considerable effect on the start of second-phase formation during solidification. Calculations predicted a TiN-type phase in all nitrogen-bearing compositions. The start of the TiN precipitation shifted to higher temperatures with increasing nitrogen content. High nitrogen levels (> $100 \mathrm{ppm}$ ) were predicted to result in TiN formation in the fully liquid state prior to the solidification of the $\gamma$ dendrites. This is also apparent from the calculated solidification paths shown in Fig. 9. Precipitation is predicted as primarily TiN-type phase at high temperatures, whereas Ti-rich carbonitrides $\mathrm{Ti}(\mathrm{C}, \mathrm{N})$ form at lower temperatures during further solidification. Solidification ends for all compositions with a terminal eutectic reaction, $\mathrm{L} \rightarrow \gamma+\mathrm{NbC}$. Calculations predict primarily $\gamma / \mathrm{NbC}$ eutectic phase, but also 


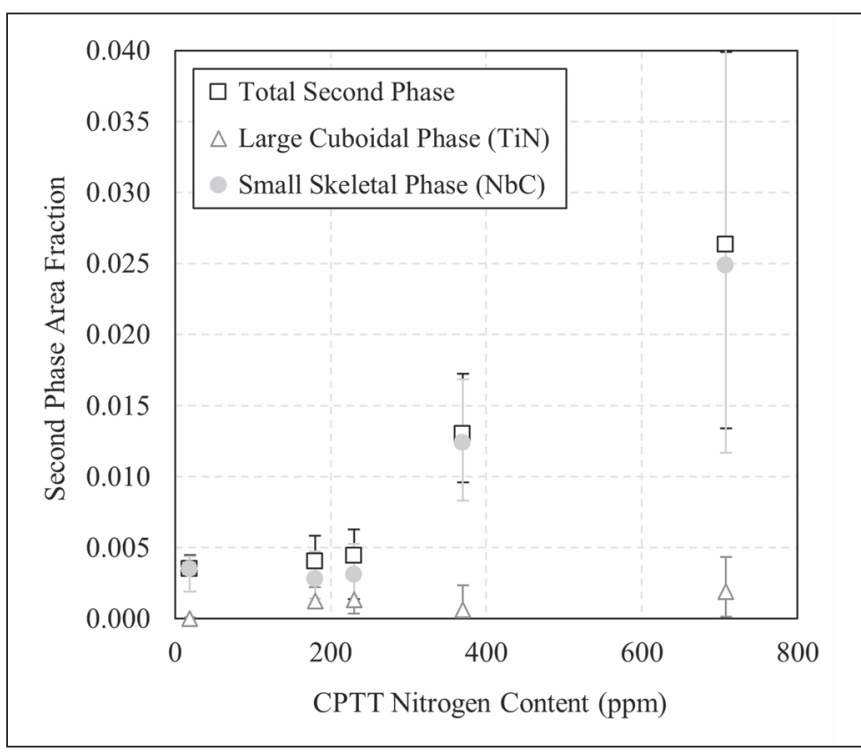

Fig. 7-Measured second-phase volume (area) fraction in cast pin microstructure as a function of nitrogen content.

more complex carbonitride $\gamma /(\mathrm{Nb}, \mathrm{Ti})(\mathrm{C}, \mathrm{N})$ type phase. Nitrogen additions (> $25 \mathrm{ppm}$ ) are predicted to result in $\gamma / \mathrm{NbC}$ formation at a lower temperature during the final stages of solidification. Table 4 summarizes the predicted solidification sequence for different nitrogen levels. A shift in solidification path occured with increasing nitrogen content so that $\mathrm{TiN}$ formation was predicted at the beginning of solidification prior to the $\mathrm{L} \rightarrow \gamma$ reaction.

The solidification temperature range (STR) was calculated as the difference between the $\gamma$ start temperature and the solidification finish temperature at a fraction solid $\left(f_{s}\right)$ of
0.95 and 0.98 , respectively (Ref. 12). As shown in Table 3, additions of nitrogen result in an increase in STR $\left(f_{s}=0.95\right)$. This is due to a change in the shape of the Scheil solidification curve. Figure 9 shows that the terminal $\mathrm{L} \rightarrow \gamma+\mathrm{NbC}$ eutectic reaction occurs at a much lower temperature in the nitrogen-bearing compositions. No increase in STR is predicted if based on a fraction solid of 0.98 .

Scheil calculations predicted an increase in total weight fraction of second phase at the end of solidification for higher nitrogen additions (see Table 3). The amount of TiN-type phase increased significantly, while the amount of $\mathrm{NbC}$ was predicted to decrease. Assuming the presence of $\mathrm{TiN}, \mathrm{NbC}$, and $\gamma$ phase only, weight fractions were converted into volume (area) fractions using densities of 5.4, 7.8, and 8.4 $\mathrm{g} / \mathrm{cm}^{3}$, respectively. Figure 10 shows that a reasonably good agreement between computational results and experimental measurements was found at lower nitrogen levels, while calculated total phase fractions were below the measured values for higher nitrogen additions. In contrast to the Scheil calculations, the experimental measurements showed a significant increase in interdendritic $\mathrm{NbC}$ at higher nitrogen content and only a slight increase in TiN-type phase.

\section{Discussion}

The computational and experimental results presented here indicate that nitrogen in $\mathrm{ERNiCr}-3$ weld metal has a significant effect on both phase formation during solidification and solidification cracking susceptibility.

Nitrogen additions substantially influence the amount and type of constituents in the final weld metal microstructure. The presence of nitrogen facilitates the formation of titanium nitrides (TiN) upon solidification. These nitrides were primarily observed in the dendrite core regions (rather
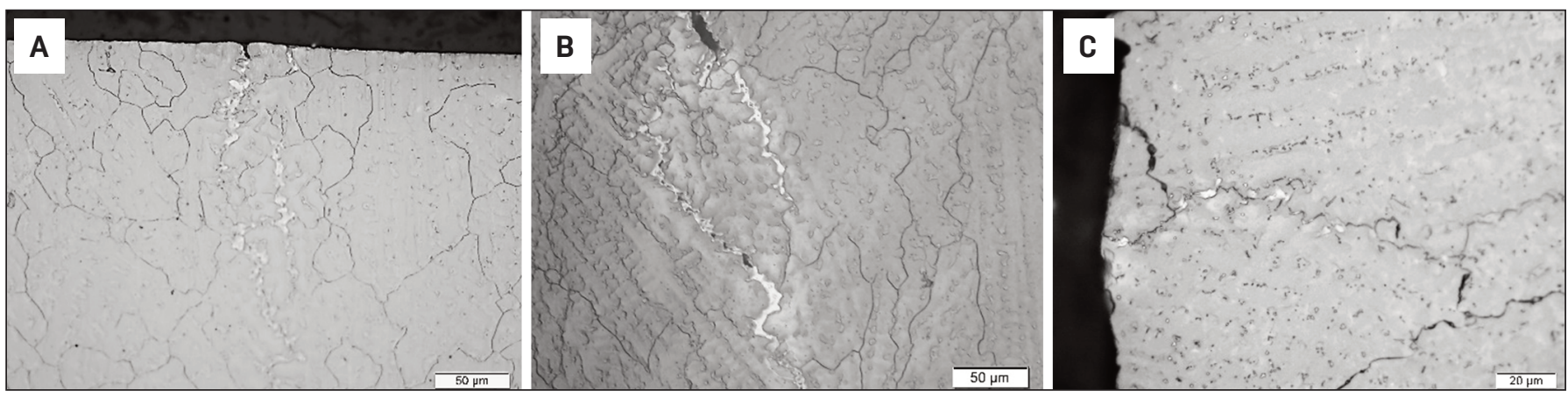

Fig. 8 - Light optical micrographs of backfilling at cracking threshold in cast pins of different nitrogen content: A - 20 ppm; B 230 ppm; C - 710 ppm.

Table 2 - Measured Total Second Phase in Cast Pins as a Function of Nitrogen Content Using Image Analysis, with Standard Deviation, 95\% Confidence Interval (CI), and Percent Relative Accuracy (RA)

\begin{tabular}{|c|c|c|c|c|}
\hline $\begin{array}{l}\text { CPTT Pin Nitrogen } \\
\text { Content (ppm) }\end{array}$ & $\begin{array}{l}\text { Avg. Measured Area \% } \\
\text { Total Second Phase }\end{array}$ & $\begin{array}{l}\text { Standard } \\
\text { Deviation }\end{array}$ & $95 \% \mathrm{Cl}$ & $\%$ RA \\
\hline 20 & 0.35 & 0.06 & 0.03 & 9.43 \\
\hline 180 & 0.40 & 0.09 & 0.05 & 12.75 \\
\hline 370 & 1.30 & 0.21 & 0.12 & 8.95 \\
\hline 710 & 2.63 & 0.73 & 0.40 & 15.37 \\
\hline
\end{tabular}


Table 3 - Solidification Start and Finish Data, and Calculated Weight Fractions (Scheil Solidification)

Nitrogen content (ppm)

First austenite $(\gamma)$ temp. $\left({ }^{\circ} \mathrm{C}\right)$

First primary TiN temp. $\left({ }^{\circ} \mathrm{C}\right)$

First primary $\mathrm{NbC}$ temp. $\left({ }^{\circ} \mathrm{C}\right)$

Solidification finish temp. $\left({ }^{\circ} \mathrm{C}\right)$

Solidification temp. range $\left({ }^{\circ} \mathrm{C}\right)$

Solidification finish temp. $\left({ }^{\circ} \mathrm{C}\right)$

Solidification temp. range $\left({ }^{\circ} \mathrm{C}\right)$

Weight fraction primary TiN

Weight fraction primary $\mathrm{NbC}$

Total weight fraction of second phase

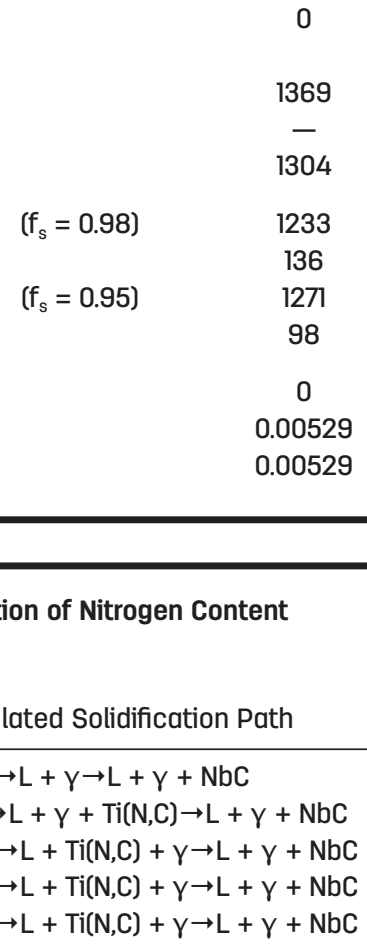

Table 4-Solidification Path as a Function of Nitrogen Content (Scheil Solidification)

\begin{tabular}{cc} 
Nitrogen Content (ppm) & Calculated Solidification Path \\
\hline 0 & $\mathrm{~L} \rightarrow \mathrm{L}+\gamma \rightarrow L+\gamma+N b C$ \\
50 & $\mathrm{~L} \rightarrow \mathrm{L}+\gamma \rightarrow L+\gamma+T i(N, C) \rightarrow L+\gamma+N b C$ \\
200 & $\mathrm{~L} \rightarrow \mathrm{L}+\mathrm{TiN} \rightarrow \mathrm{L}+\mathrm{Ti}(\mathrm{N}, \mathrm{C})+\gamma \rightarrow L+\gamma+N b C$ \\
500 & $\mathrm{~L} \rightarrow \mathrm{L}+\mathrm{TiN} \rightarrow \mathrm{L}+\mathrm{Ti}(N, \mathrm{C})+\gamma \rightarrow L+\gamma+N b C$ \\
800 & $\mathrm{~L} \rightarrow \mathrm{L}+\mathrm{TiN} \rightarrow \mathrm{L}+\mathrm{Ti}(\mathrm{N}, \mathrm{C})+\gamma \rightarrow L+\gamma+N b C$
\end{tabular}

than in interdendritic regions), which indicates that this precipitation reaction starts in the fully liquid state prior to the start of the solidification of the gamma $(\gamma)$ phase. The large size and cuboidal morphology of the titanium nitrides is another indication that they form, prior to $\gamma$ solidification, when there is no growth restriction by diffusive supply of titanium and nitrogen from the interdendritic liquid (Ref. 13). Scheil calculations confirm this shift in solidification sequence, such that at high nitrogen additions (>100 ppm) TiN precipitation is predicted to occur prior to the $\gamma$ start temperature (see Table 4). It appears that in compositions with sufficiently high nitrogen content, the nitrogen solubility in the liquid phase was exceeded, causing titanium nitrides to form in an early stage of solidification. Some of the titanium nitrides probably nucleate from oxide inclusions, as has been previously reported in other nickel-based alloys (Ref. 14). This is supported by the fact that most of the observed larger nitrides show a nucleation core, probably an oxide particle - Fig. 6B.

As discussed, it is reasonable to consider that solidification in the high nitrogen compositions of $\mathrm{ERNiCr}-3$ weld metal starts with the precipitation of numerous titanium nitrides in the liquid phase. The high melting point of these nitrides $\left(2927^{\circ} \mathrm{C}\right.$ (Ref. 15)) makes them potent nucleating agents for the formation of more complex $(\mathrm{Ti}, \mathrm{Nb})(\mathrm{C}, \mathrm{N})$ carbonitrides during further solidification. Numerous large, cuboidal particles highly enriched in both titanium and niobium, probably mixed carbonitrides, were observed in the solidified microstructures - Fig. 6 . No further high magnification microscopy was performed. However, it has been previously shown for similar particles in other nickel base weld metals that these carbonitrides have a complex structure of a niobium carbide $(\mathrm{NbC})$ shell nucleating on and surrounding the titanium nitride core (Refs. 16, 17). The favorable nucleation of niobium carbides on titanium nitrides has been reported earlier (Refs. 16-18), and corresponds to the same cubic crystal structure of both precipitates and very similar lattice parameters for $\mathrm{NbC}\left(\mathrm{a}_{0}=0.430-0.470\right)$ and $\operatorname{TiN}\left(\mathrm{a}_{0}=0.4240\right)$ (Ref. 19). Note that not all of the observed titanium nitrides are enriched in niobium. Some nitride particles could have been incorporated in the growth of the gamma $(\gamma)$ dendrites before the temperature dropped to the point for carbide nucleation (Ref. 14).

During further solidification, niobium and carbon continue to segregate to the liquid phase. Any titanium nitride or carbonitride will likely act as heterogeneities for the nucleation of niobium carbides. In fact, the formation of niobium carbide arms on the surface of preexisting titanium nitrides was frequently observed in the solidified microstructures, especially closer to the interdendritic regions - Fig. 6 . Some of the niobium carbide arms are enriched in titanium by both diffusion from nitrides and from the liquid. Once the eutectic temperature is reached, the remaining interdendritic liquid phase transforms into the $\gamma / \mathrm{NbC}$ eutectic constituent. Niobium carbides were observed in all ERNiCr3 weld metals irrespective of nitrogen content. Their location in the interdendritic regions and small, skeletal morphology indicated that these carbides form in the final liquid at the end of solidification when growth rates are restricted by the available liquid volume (Ref. 13). Experimental measurements showed that high nitrogen additions promote a considerable increase in interdendritic carbide-type phase - Fig. 7. Considering the favorable nucleation of carbides on preexisting titanium nitrides, it is reasonable to conclude that this increase is a result of the presence of numerous titanium nitride nuclei in the high-nitrogen compositions. Scheil calculations predict a significant increase in titanium nitrides, but not in eutectic $\gamma / \mathrm{NbC}$ phase at high nitrogen levels. This difference might be because the nucleation of the carbide phase on preexisting nitride particles was not considered in the solidification modeling.

The CPTT showed that nitrogen additions to $\mathrm{ERNiCr}-3$ weld metal led to a dramatic increase in cracking susceptibility. The results correlate well with industry experience on solidification cracking issues in filler metal heats with in- 


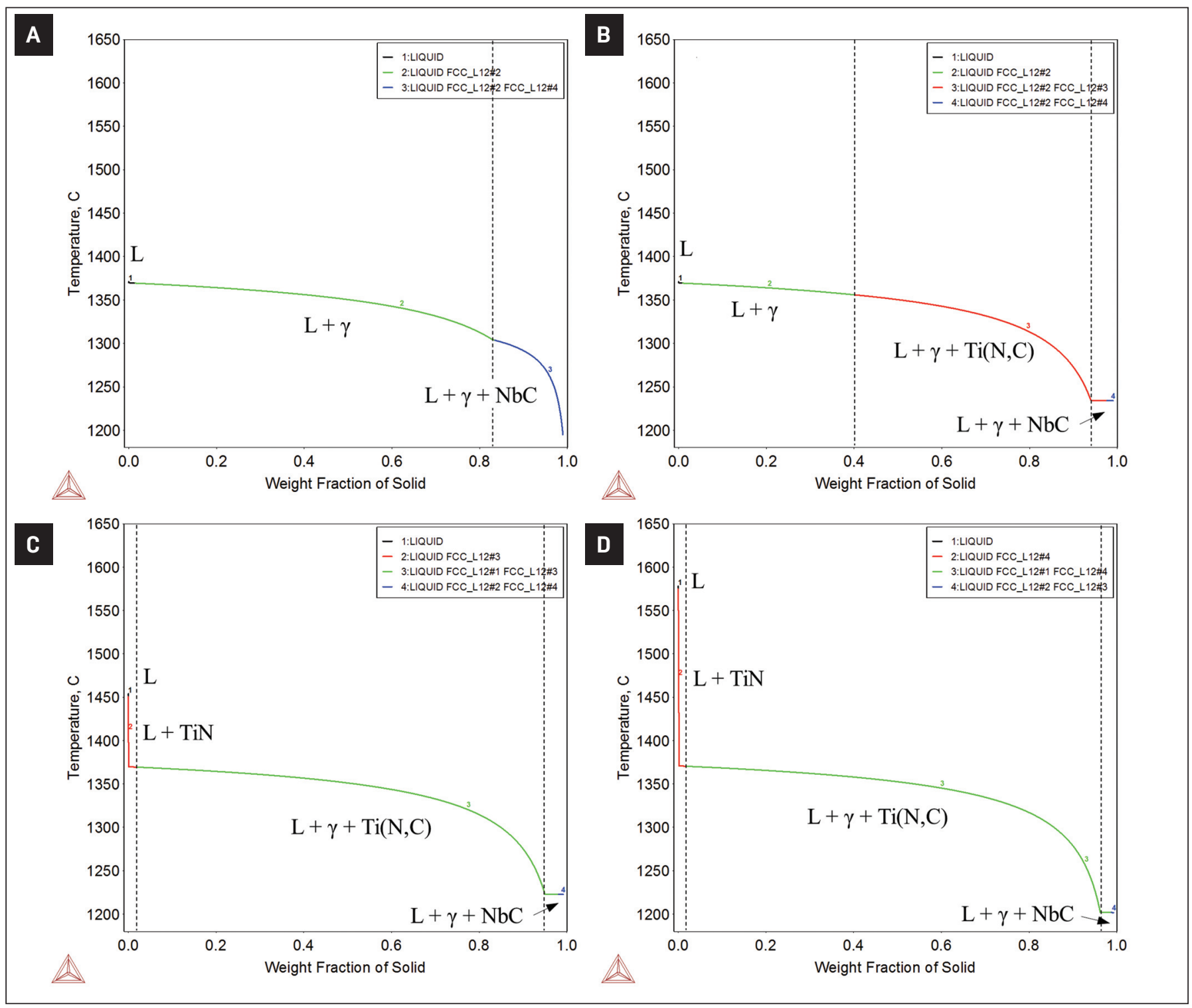

Fig. $9-$ Calculated solidification paths (Scheil solidification) for different nitrogen contents: A -0 ppm; B -50 ppm; C - 200 ppm; $D-500$ ppm.

creased nitrogen content (Refs. 5, 20). It was hypothesized that an increase in interdendritic second phase due to nitrogen influences the backfilling phenomenon that can heal cracks. Extensive backfilling was not observed in the solidified microstructures irrespective of nitrogen content. Therefore, a reduced backfilling effect caused by an increase in the interdendritic phase did not seem to be supported by the metallographic evidence - Fig. 8. The amount of second phase appeared to be too low to allow for crack healing to occur. The measured phase fractions were less than 0.5 vol- $\%$ without nitrogen additions, and increased to a maximum of 4 vol-\% at the highest nitrogen content - Fig. 7. Crack healing by eutectic backfilling in other nickel base weld metals was reported to be significant at levels above $~ 15$ vol-\% phase fraction (Ref. 9).

However, at the low phase fractions that were measured in this study, an increase in liquid phase at the end of solidification due to nitrogen could contribute to an increase in solidification cracking susceptibility. More liquid is available in interdendritic regions and along solidification grain boundaries, creating a crack-susceptible microstructure during the final stages of solidification. However, when the cracking susceptibility curve from Fig. 4 is plotted over the corresponding phase fraction, it is apparent that the initial drop in LCT with increasing nitrogen content occurs without a significant increase in second phase - Fig. 11. It is not the increase in interdendritic phase that is affecting the cracking susceptibility in the tested $\mathrm{ERNiCr}-3$ weld metal, at least not at the lower nitrogen levels.

Scheil calculations confirmed the strong effect of nitrogen additions on the amount and sequence of second-phase formation during solidification of ERNiCr-3 weld metal. High nitrogen levels (> $100 \mathrm{ppm}$ ) changed the solidification sequence by facilitating titanium nitride formation at the beginning of the solidification process. During further solidification, all of the involved solutes, i.e., nitrogen, carbon, ti- 


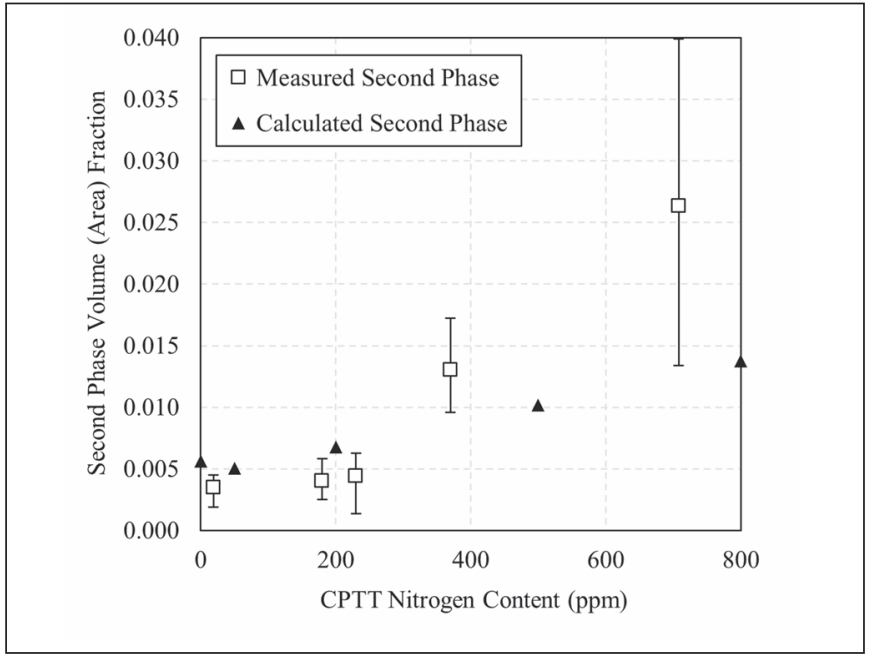

Fig. 10 - Calculated vs. measured second-phase fractions as a function of nitrogen content.

tanium, and niobium, segregated to the liquid phase. Therefore, their content at the saturation solubility is a strong function of temperature. Precipitation reactions prior to and at the eutectic temperature are altered as a function of solute content in the liquid phase, as will be the solute concentration in the final liquid along solidification grain boundaries. Scheil calculations show that the presence of nitrogen shifts the eutectic $\mathrm{L} \rightarrow \gamma+\mathrm{NbC}$ reaction to lower start temperatures, and results in an increase in the solidification temperature range (see Table 3 ). When the cracking susceptibility curve is plotted with the corresponding predicted solidification temperature range, the drop in LCT at low nitrogen levels correlates well with an increase in solidification temperature range - Fig. 12.

Ongoing work will concentrate on the interactive effect of the different interstitial $(\mathrm{C}, \mathrm{N})$ and solute $(\mathrm{Nb}, \mathrm{Ti})$ elements on phase formation during solidification, and the composition of the segregated liquid remaining at the end of solidification. The characteristics of the final liquid also directly influence its ability to flow and wet the solidification grain boundaries. Hence, liquid film properties at the weld metal grain boundaries can play a significant role on solidification cracking, as currently under investigation in other nickel-base alloys (Ref. 21). With regard to future work on the effect of nitrogen in nickel-base weld metals, it is also important to point out that the results of this work showed a considerable difference in nitrogen content between the as-deposited weld metal and the cast pin samples used for weldability testing. This loss of nitrogen during remelting needs to be considered when generating data in further studies.

\section{Conclusions}

Additions of nitrogen to ERNiCr-3 weld metal resulted in an increase in solidification cracking susceptibility in the cast pin tear test (CPTT). The results reflect industry experience, which shows higher cracking susceptibility with increased nitrogen content in this filler metal.

The presence of nitrogen substantially influenced the amount and type of second-phase constituents in the final

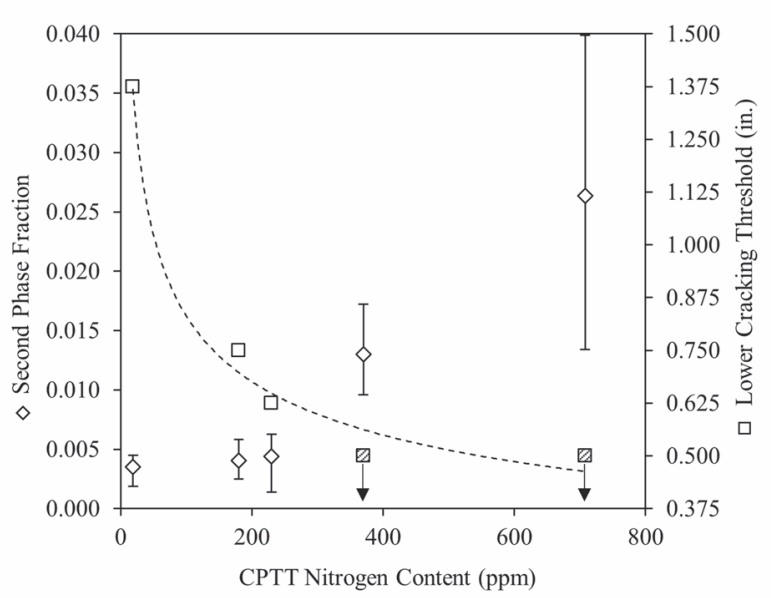

Fig. 11 - Cracking susceptibility (LCT) and corresponding measured total second-phase fraction as a function of nitrogen content.

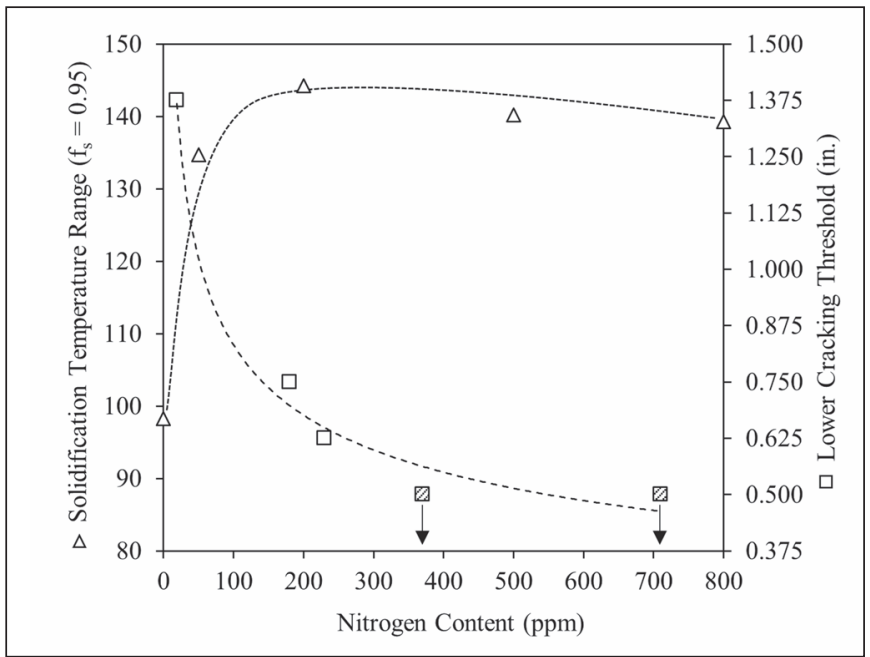

Fig. 12 - Cracking susceptibility (LCT) and corresponding calculated solidification temperature range (STR) as a function of nitrogen content.

solidification structure of ERNiCr-3 weld metal.

Nitrogen additions facilitated the formation of large, cuboidal Ti-rich nitrides and more complex $(\mathrm{Ti}, \mathrm{Nb})(\mathrm{C}, \mathrm{N})$ carbonitrides. Their location in dendrite core regions indicated these particles form prior to the start of gamma solidification. Some act as nucleation sites for eutectic $\mathrm{Nb}$-rich carbides $(\mathrm{NbC})$ that are present in the interdendritic regions.

The amount of interdendritic NbC-type phase in the final solidification microstructure increased when nitrogen was added to the weld metal, especially at high nitrogen additions. However, this slight increase in interdendritic second phase did not correlate to the dramatic increase in solidification cracking susceptibility that is observed at low nitrogen content.

Scheil calculations confirmed high nitrogen additions changed the solidification path by facilitating nitride formation early during the solidification process, and increased the 
amount of second-phase constituents. The presence of nitrogen also shifted the eutectic $\gamma / \mathrm{NbC}$ reaction at the end of solidification to lower start temperatures, which resulted in an increase in the solidification temperature range (STR). This increase in STR at low nitrogen levels correlates with the observed increase in solidification cracking susceptibility.

\section{Acknowledgments}

This work was supported by the NSF sponsored Industry/University Cooperative Research Center (I/UCRC): Manufacturing and Materials Joining and Innovation Center (Ma2JIC).

\section{References}

1. Materials Reliability Program: Technical Basis for Preemptive Weld Overlays for Alloy 82/182 Butt Welds in PWRs (MRP-169) Revision 1. 2008. Palo Alto, Calif.: EPRI; San Jose, Calif.: Structural Integrity Associates Inc., MRP-169.

2. Hänninen, H., Brederholm, A., and Saukkonen T. 2008. Hot Cracking Susceptibility of Ni-Base Alloy Dissimilar Metal Welds. Hot Cracking Phenomena in Welds II, eds. Böllinghaus, T., Herold, H., Cross, C. E., and Lippold, J. C. Berlin: Springer, pp. 171-191. DOI: 10.1007/978-3-540-78628-3_10

3. Alexandrov, B. T., and Lippold, J. C. 2013. Use of the cast pin tear test to study solidification cracking. Welding in the World 57(5): 635-648. DOI: 10.1007/s40194-013-0061-3

4. Przybylowicz, E., Alexandrov, B. T., Lippold, J. C., and McCracken, S. 2016. Weldability evaluation of high chromium, Nibase filler metals using the cast pin tear test. Cracking Phenomena in Welds IV, eds. Böllinghaus, T., Lippold, J. C., and Cross, C. E., Springer International Publishing, pp. 269-288. DOI: 10.1007/ 978-3-319-28434-7_13

5. Orr, M. R., Lippold, J. C., and Argentine, F. 2017. Evaluation of solidification cracking susceptibility in ERNiCr-3 (Filler Metal 82) weld metal using the cast pin tear test. Welding in the World 61(5): 935-944. DOI: 10.1007/s40194-017-0473-6

6. Savage, W. F., and Dickinson, D. W. 1972. Electron microanalysis of backfilled hot cracks in Inconel 600. Welding Journal 51(11): 555-s to 562-s.

7. Lippold, J. C., Sowards, J. W., Murray, G. M., Alexandrov, B. T., and Ramirez, A. J. 2008. Weld solidification cracking in solidsolution strengthened Ni-base filler metals. Hot Cracking Phenomena in Welds II, eds. Böllinghaus, T., Herold, H., Cross, C. E., and Lippold, J. C. Berlin: Springer, pp. 147-170. DOI: 10.1007/978-3-54078628-3_9

8. Huang, C., Cao, G., and Kou, S. 2004. Liquation cracking in partial penetration aluminum welds: Assessing tendencies to liquate, crack and backfill. Science and Technology of Welding and Join- ing 9(2): 149-157. DOI: 10.1179/136217104225017071

9. Wheeling, R. A., and Lippold, J. C. 2016. Solidification cracking susceptibility of $\mathrm{Ni30} \mathrm{Cr}$ weld metals with variable niobium and molybdenum. Welding Journal 95(7): 229-s to 238-s.

10. Luskin, T. C. 2013. Investigation of Weldability in High- $\mathrm{Cr}$ Ni-base Filler Metals. Master thesis, The Ohio State University, Columbus, Ohio.

11. DuPont, J. N., Marder, A. R., Notis, M. R., and Robino, C. V. 1998. Solidification of Nb-bearing superalloys: Part II.

Pseudoternary solidification surfaces. Metallurgical and Materials Transactions A 29(11): 2797-2806. DOI: 10.1007/s11661-9980320-x

12. Lippold, J. C. Nov. 2016. Progress on the Development of Weldable Ni-30Cr Filler Metals for Nuclear Applications. Alloy 690/52/152 PWSCC Research Collaboration Meeting, Tampa, Fla.

13. Mitchell, A. 2005. The precipitation of primary carbides in IN718 and its relation to solidification conditions. Superalloys 718, 625, 706 and Derivatives, pp. 299-310.

14. Cockcroft, S. L., Degawa, T., Mitchell, A., Tripp, D. W., and Schmalz, A. J. 1992. Inclusion precipitation in superalloys. Superalloys 1992, pp. 577-586.

15. Lengauer, W. 2000. Transition metal carbides, nitrides, and carbonitrides. Handbook of Ceramic Hard Materials, ed. Riedel, R. Weinheim, Germany: Wiley, pp. 202-252. DOI: 10.1002/ 9783527618217.ch7

16. Mitchell, A., Schmalz, A. J., Schvezov, C., and Cockcroft, S. L. 1994. The precipitation of primary carbides in Alloy 718. Superalloys 718, 625, 706 and Various Derivatives, pp. 65-78.

17. Silva, C. C., de Miranda, H. C., Motta, M. F., Farias, J. P., Afonso, C. R. M., and Ramirez, A. J. 2013. New insight on the solidification path of an alloy 625 weld overlay. Journal of Materials Research and Technology 2(3): 228-237. DOI: 10.1016/j.jmrt.2013. 02.008

18. Formenti, A., Eliasson, A., Mitchell, A., and Fredriksson, H. 2005. Solidification sequence and carbide precipitation in Ni-base superalloys IN718, IN625 and IN939. High Temperature Materials and Processes 24(4): 239-258. DOI: 10.1515/HTMP.2005.24.4.239

19. Geddes, B., Leon, H., and Huang, X. 2010. Superalloys: Alloying and Performance. Materials Park, Ohio: ASM International. ISBN: 978-1-61503-040-8.

20. Orr, M. R. 2016. Solidification Cracking Performance and Metallurgical Analysis of Filler Metal 82. Master thesis, The Ohio State University, Columbus, Ohio.

21. Wheeling, R. A., and Lippold, J. C. 2017. Effect of composition on grain boundary wetting characteristics in $\mathrm{Ni}-30 \mathrm{Cr}$ weld metal. Welding in the World 61(2): 315-324. DOI: 10.1007/s40194016-0411-z

MICHAEL R. ORR, CAROLIN FINK (fink.242@osu.edu), and JOHN C. LIPPOLD are with The Ohio State University, Welding Engineering Program, Columbus, Ohio. FRANK ARGENTINE is from BWX Technologies Inc., Barberton, Ohio. 